\title{
Open-ocean convection in the Greenland Sea: preconditioning through a mesoscale chimney and detectability in SAR imagery studied with a hierarchy of nested numerical models
}

\author{
Alexey Androsov*1, Angelo Rubino ${ }^{1,2}$, Roland Romeiser ${ }^{1}$, and Dmitry V. Sein ${ }^{3}$ \\ ${ }^{1}$ Institut für Meereskunde der Universität Hamburg, Hamburg, Germany \\ ${ }^{2}$ Dipartimento di Scienze Ambientali, Università Ca'Foscari di Venezia, Venice, Italy \\ ${ }^{3}$ Max-Planck-Institut für Meteorologie, Hamburg, Germany
}

(Manuscript received February 2, 2005; in revised form September 2, 2005; accepted September 29, 2005)

\begin{abstract}
Aspects of the hydrodynamics of the Greenland Sea were investigated through a hierarchy of nested numerical models. The simulations were particularly conceived to study, under realistic conditions, the hydrodynamics induced by the presence of a convectively generated oceanic mesoscale chimney as well as its "long-term" influence on the local convective activity. To this purpose, a very high resolution, fully non-hydrostatic 3D model capable of simulating submesoscale convective vertical plumes was nested into an ocean-ice, regional hydrostatic 3D model which was initialised and forced through the global, coupled atmosphere ocean 3D REMO/MPI-OM model. In the central part of the Greenland Sea, the hydrological structure of an observed, convectively generated oceanic mesoscale chimney and a corresponding reconstructed velocity field were imposed as a part of the forcing for the non-hydrostatic numerical model. Two different, "short-term" realistic scenarios were simulated corresponding, respectively, to episodes characterized by a strong mean oceanic heat loss and by a weak mean oceanic heat gain in the central Greenland Sea. In order to evaluate the role played by mesoscale convective chimneys in promoting preconditioning to open-ocean deep-penetrating convection, two "long-term" simulations of the hydrodynamics of the Greenland Sea were performed using the same model hierarchy and the forcing as described above. The two runs differed merely in that only in one of them the hydrological and velocity structure of a convective chimney were inserted in the central Greenland Sea as a part of the forcing. The dependence of simulated surface convergence patterns on grid step in the central Greenland Sea was also investigated in order to assess the capability of numerical models of predicting the detectability of convective events in synthetic aperture radar imagery.
\end{abstract}

\begin{abstract}
Zusammenfassung
Aspekte der Hydrodynamik der Grönland-See wurden mit einer Hierarchie verschachtelter numerischer Modelle untersucht. Die Simulationen waren vor allem dazu gedacht, die Hydrodynamik, die sich aus der Anwesenheit eines konvektiv erzeugten ozeanischen mesoskaligen "Chimney" ergibt, sowie dessen langfristigen Einfluss auf die lokale konvektive Aktivität unter realistischen Bedingungen zu untersuchen. $\mathrm{Zu}$ diesem Zweck wurde ein hochauflösendes, voll nicht-hydrostatisches dreidimensionales Modell, das sub-mesoskalige konvektive vertikale "Plumes" simulieren kann, in ein regionales hydrostatisches dreidimensionales Ozean-Eis-Modell eingebaut, welches durch das globale, gekoppelte Atmosphäre-OzeanModell REMO/MPI-OM initialisiert und angetrieben wurde. Im zentralen Teil der Grönland-See wurde die hydrologische Struktur eines beobachteten konvektiv erzeugten ozeanischen mesoskaligen "Chimney" und ein entsprechendes rekonstruiertes Geschwindigkeitsfeld als Teil des Antriebs für das nichthydrostatische numerische Modell eingeblendet. Zwei verschiedene realistische Kurzzeit-Szenarien wurden simuliert, entsprechend Episoden, die durch einen starken mittleren ozeanischen Wärmeverlust bzw. durch einen schwachen mittleren ozeanischen Wärmegewinn in der zentralen Grönland-See geprägt sind. Um die Rolle der mesoskaligen konvektiven "Chimneys" bei der Förderung tiefreichender Konvektion im offenen Ozean beurteilen zu können, wurden zwei Langzeit-Simulationen der Hydrodynamik der GrönlandSee mit der selben Modell-Hierarchie und dem selben Antrieb wie oben beschrieben durchgeführt. Die beiden Läufe unterschieden sich im wesentlichen dadurch, dass nur im einen Fall die hydrologische Struktur und das Geschwindigkeitsfeld eines konvektiven "Chimney" als Teil des Antriebs in die zentrale GrönlandSee eingeblendet wurden. Auch die Abhängigkeit der simulierten Oberflächenkonvergenzmuster von der Gitterauflösung in der zentralen Grönland-See wurde analysiert, um die Fähigkeit von numerischen Modellen zu beurteilen, die Erkennbarkeit von Konvektionsereignissen in Synthetic-Aperture-Radar-Bildern vorherzusagen.
\end{abstract}

${ }^{*}$ Corresponding author: Alexey Androsov, Universität Hamburg, Zentrum für Meeres- und Klimaforschung, Institut für Meereskunde, Bundesstr. 53, 20146 Hamburg, Germany, e-mail: androssov@ifm.uni-hamburg.de 


\section{Introduction}

Open ocean deep convection, which sets and maintains the water mass characteristics of the abyssal ocean, is known to be an intermittent process which involves various temporal and spatial scales (MARSHALL and SCHOTT, 1999). In a first preconditioning stage it is usually a cyclonic gyre that enables weakly stratified interior water to reach the near-surface layers. During winter, the stratification within these layers is substantially eroded by large buoyancy loss, which causes a direct exposition of interior water to the atmosphere. Cold air outbreaks are then able to trigger the formation of vigorous small-scale vertical plumes, which can actively distribute newly formed surface dense water within the water column. The integral effect of the plume activity consists of a mixed patch ("chimney") having spatial scales which range from several tens to several hundreds of km (see, e.g., the MEDOC Group 1970). From its core, mesoscale eddies in nearly geostrophic equilibrium may detach, which are able to horizontally exchange water with the surroundings.

In the Greenland Sea, open-ocean deep convection has been put in relation to ice-induced preconditioning (RoACH et al., 1993; SCHOTT et al., 1993; VISBECK et al., 1995). In a first stage, the mixed layer density increases under ice due to brine injection during ice formation and due to cooling to the freezing point. A mixed layer deepening takes thus place, which continues throughout the winter. In an ice-free region named "Nord Bukta" the direct exposition of interior water to the atmosphere is responsible for open-ocean deep convection by strong cold air outbreaks in late winter. Note, however, that, because open-ocean deep convection in the Greenland Sea has been rather weak in the last years, this chain of events is based only on a few observations (MARSHALL and SCHOTT, 1999). Recent observations suggest, instead, that mesoscale vortices, which are commonly encountered there, play a fundamental role in the preconditioning of the central Greenland Sea to deep convection as they act as focussing spots for convective events (GASCARD et al., 2002). Such a capability of mesoscale eddies had been demonstrated theoretically by LEGG and MARSHALL (1998). The stages of life of a convective mesoscale vortex can be summarized as follows: At the end of the winter season its surface outcropping area decreases as, with the weakening of strong cold air outbreaks, mixing with adjacent waters spins down the vortex velocity field. Eventually, the vortex is transformed into a surface/intermediate mesoscale coherent feature, which may survive the summer season, and possibly facilitate convective events during next winter (WADHAMS et al., 2002). This climatically relevant evolution of convectively generated mesoscale vor- tices, which has been conjectured on the base of a few observations (WADHAMS et al., 2002; GASCARD et al., 2002) cannot be captured by large-scale numerical models, whose horizontal grid steps are typically larger than the internal Rossby radius of deformation. Moreover, as far as the numerical simulation of open-ocean convective activity induced by the presence of mesoscale chimneys in the Greenland Sea is concerned, a very high resolution in the central part of the basin is required, together with realistic initial conditions and realistic oceanic and atmospheric boundary conditions and forcing. These elements are implemented for the first time in the present study, using a hierarchy of nested numerical models: a very high resolution, fully nonhydrostatic 3D model, in which the structure of a realistic mesoscale chimney similar to that observed by WADHAMS et al. (2002) in the central Greenland Sea is imposed, was nested into an ocean-ice, hydrostatic regional model, which was initialised and forced (using six-hourly data) through the global, coupled atmosphere ocean 3D REMO/MPI-OM model (JACOB and Podzun, 1997; MAIER-Reimer, 1997). Two different, short-term realistic scenarios were simulated corresponding, respectively, to a strong mean oceanic heat loss and to a weak mean oceanic heat gain in the central Greenland Sea (strong and weak atmospheric scenarios in the following). In the strong atmospheric scenario, the chimney resulted significantly magnified by the vigorous convective plume activity emerging almost exclusively within its body. In the weak atmospheric scenario, instead, the chimney tended to transform into an intermediate vortex. In both cases, however, the chimneys largely preserved their coherence. The role played by mesoscale convective chimneys in promoting preconditioning to open-ocean, deep penetrating convection was then investigated through the analysis of long-term simulations (17 months) of the hydrodynamics of the Greenland Sea with the model hierarchy and with the forcing described above. An analysis of the model results demonstrates that the chimney was able to persist as a coherent feature in the central Greenland Sea throughout the whole simulation period successive to its insertion (15 months). It constituted a significant element of preconditioning to next convective events, as the water mass stability was significantly eroded in the central Greenland Sea due to its presence. A sensitivity study elucidates the dependence of simulated surface convergence patterns, which, substantially, constitute the link between sea surface signatures of oceanic and atmospheric phenomena and radar images of the sea surface, on grid step. It is found that only very high horizontal resolutions $(\mathrm{o}(100 \mathrm{~m}))$ yield realistic intensities of surface signatures of frontal features like those produced by deep penetrating convection. On this basis, the capability of numerical models of predicting the detectability of 


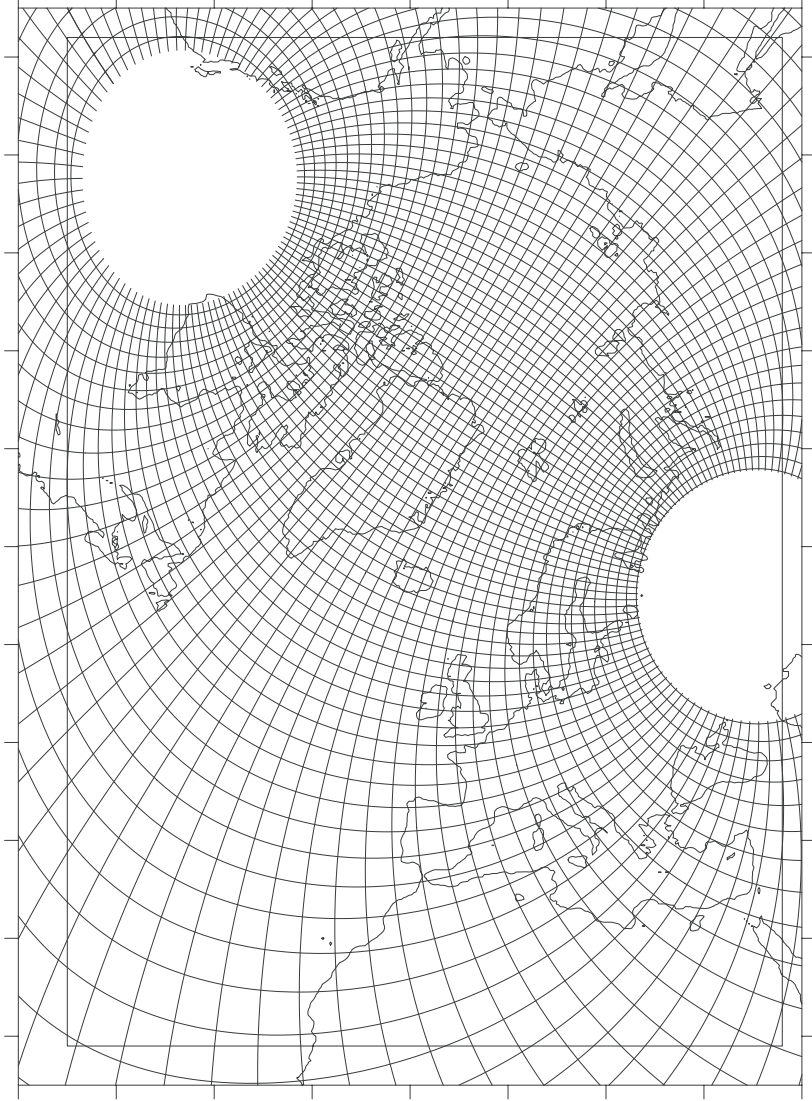

a)
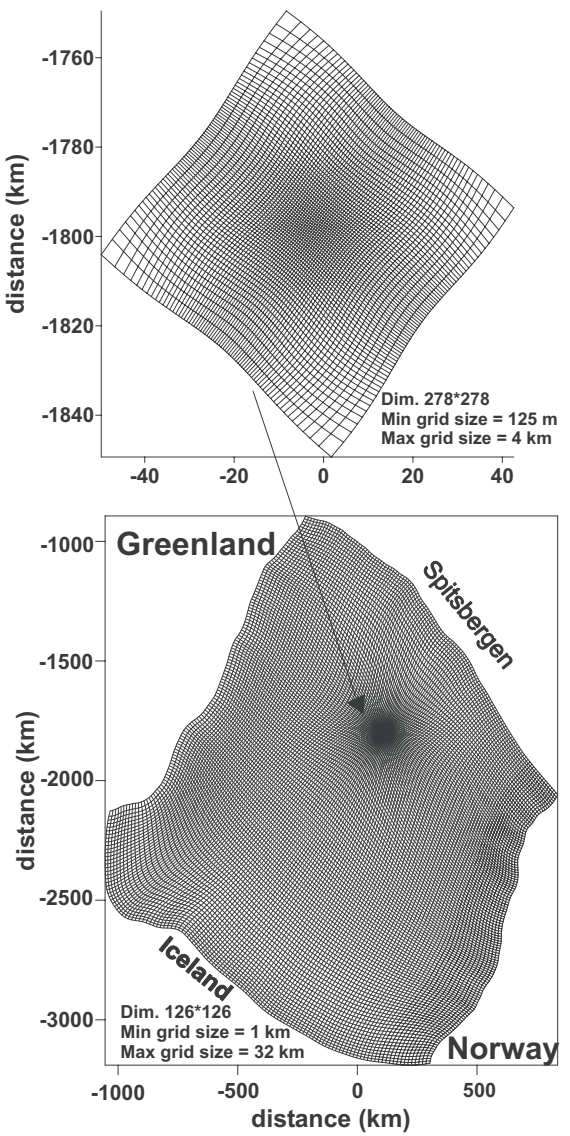

b)

Figure 1: Model configuration: a) Grid for REMO/MPI-OM; b) Curvilinear grid for the regional model (lower panel) and for the nonhydrostatic model (upper panel).

convective events in synthetic aperture radar imagery is discussed.

\section{Model characteristics and nesting strategy}

The model configuration used in the present study is depicted in Fig. 1: the regional as well as the non-hydrostatic 3D model are different versions of the hydrostatic/nonhydrostatic 3D curvilinear coordinate hydrodynamic model GNOM (GNOM = General Non-hydrostatic Ocean Model). This model solves a boundary-value problem for the equation of motion, continuity, temperature, and salinity in an arbitrary 3D domain (ANDROSOV et al., 1995; MAHADEVAN et al., 1996; ANDROSOV et al., 2002; ROMEISER et al., 2004; ANDrosov and Voltzinger, 2005). Horizontally, curvilinear, boundary-fitted coordinates are used, while, vertically, the model uses a $\sigma$-coordinate approach. The model is two-way coupled to a thermodynamic ice model similar to the one of HIBLER (1979). The initialisation of the regional model was performed using the hydrographic and velocity fields obtained by the MPI-OM global model (MAIER-REIMER, 1997), while its forcing was imposed six-hourly at the model open boundaries as well as at the sea surface from the REMO/MPI-OM coupled model. The REMO/MPI-OM coupled model is a high resolution atmosphere-ocean-ice model. The atmospheric component consists of a REgional atmosphere MOdel (REMO) (JACOB and PODZUN, 1997) with about $1^{\circ}$ horizontal resolution (see Fig. 1,) which includes the Artic and the North Atlantic oceans to about $20^{\circ} \mathrm{N}$. The oceanic component (Max Planck Institute Ocean Model) is a 3D truly global ocean model. It utilizes conformal mapping and it has a very high horizontal resolution in the Artic and North Atlantic oceans with a maximum of about $20 \mathrm{~km}$, which gradually coarsens outside the focus region. In this model, a state-of-the-art sea ice model including snow and viscous-plastic rheology is implemented. The models are coupled using OASIS coupler developed by CERFACS (VALCKE et al., 2000).

The non-hydrostatic 3D model was initialised by interpolating the data obtained by the regional GNOM model. In its central region, however, the structure of an observed mesoscale chimney (WADHAMS et al., 2002) and the corresponding velocity field obtained by running GNOM diagnostically were imposed. Vertical sections 


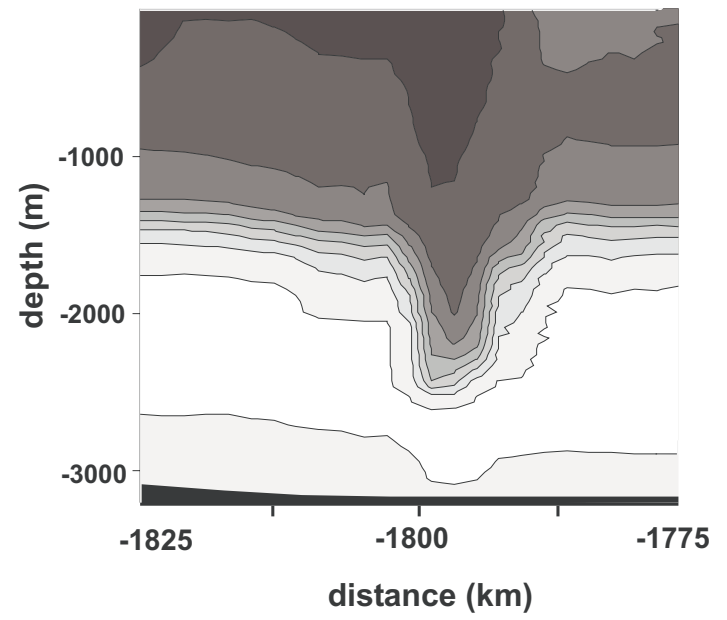

S (PSU)

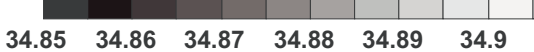

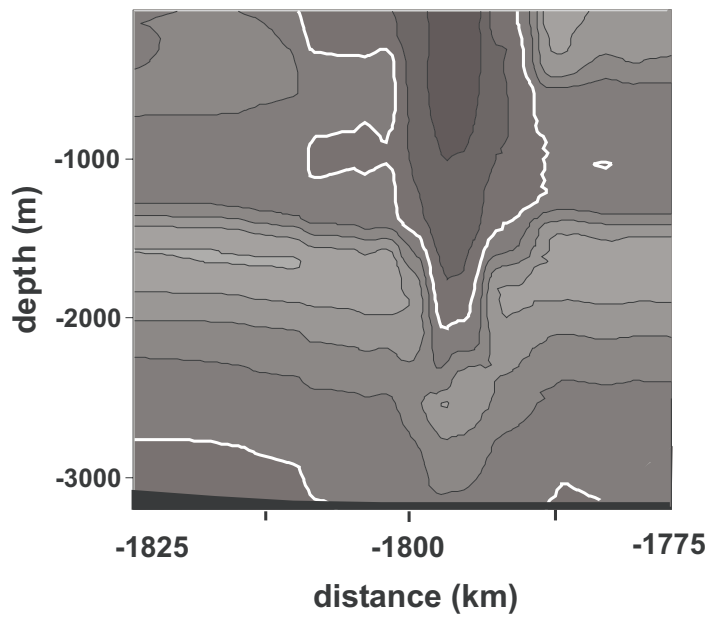

$\mathrm{T}\left({ }^{\circ} \mathrm{C}\right)$

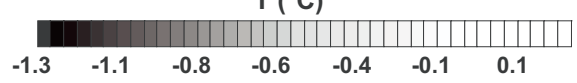

Figure 2: Vertical sections of temperature and salinity showing the structure of the observed chimney as introduced in the non-hydrostatic model. Note that the white line indicates the $-0.92^{\circ} \mathrm{C}$ isotherm, which is considered here as the isotherm separating the observed chimney from the ambient ocean.

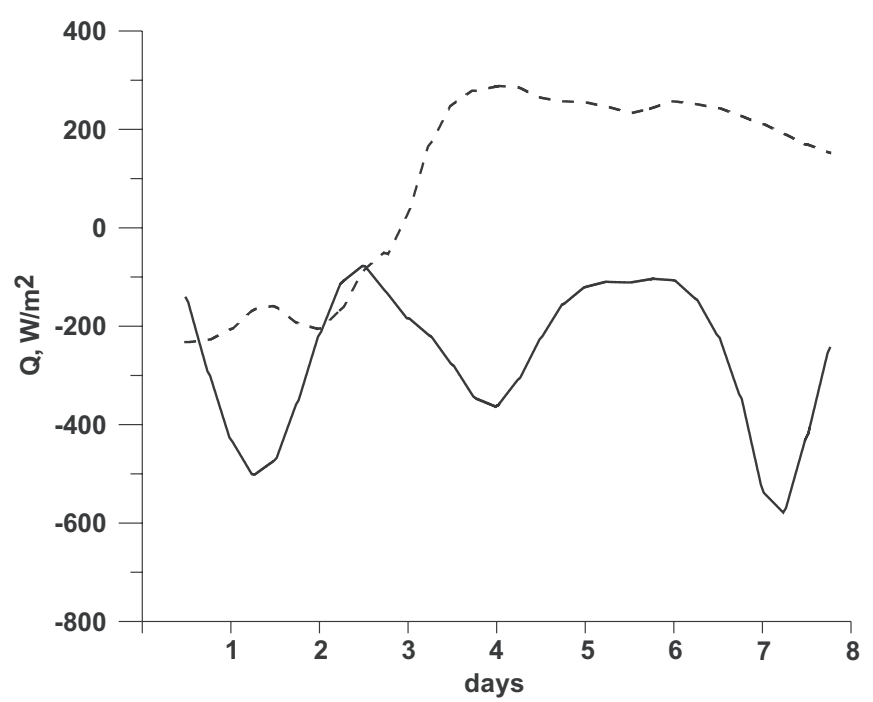

Figure 3: Imposed heat fluxes averaged over the focus region. The dotted line refers to the scenario with a weak atmospheric forcing, the solid line to the scenario with a strong atmospheric forcing.

of temperature and salinity showing the structure of the observed chimney as interpolated in the non-hydrostatic model are depicted in Fig. 2. We had to run the model for two weeks in order to reach an adjusted state which was then considered as the initial state for our simulations. In the simulations performed using GNOM we used heat and fresh water fluxes and wind stress at the sea surface as well as (only in the regional model) water mass characteristics and normal velocities at the open boundaries taken from REMO/MPI-OM. Due to its curvilinear grid approach, GNOM allows for an increased resolution (focusing) in regions of special interest (see Fig. 1). In the present study the grid size varies thus between $125 \mathrm{~m}$ in the focus region of the non-hydrostatic model and about $32 \mathrm{~km}$ at the open boundaries of the regional model (see Fig. 1). This characteristic of GNOM is especially valuable, as it allows for an accurate simulation of oceanic submesoscale features, like, e.g., convective plumes, in selected areas.

\section{Short-term numerical experiments}

In order to investigate in detail aspects of the evolution of the convective chimney under realistic conditions including deep penetrating convection, two different short-term numerical experiments were carried out, using the hierarchy of models described below, over a period of 8 days. Such periods refer to episodes characterized, respectively, by a strong mean oceanic heat loss and by a weak mean oceanic heat gain in the central Greenland Sea ("strong" and "weak" atmospheric scenarios in the following) and were chosen as large enough to encompass the typical development of mesoscale atmospheric disturbances over the area of the Greenland Sea. The experiments are thus identical in their oceanic initial conditions as well as in their oceanic active boundary conditions, but they substantially differ in their atmospheric forcing, which originates from two different realizations of the REMO model for wintertime in the Greenland Sea. In Fig. 3 the imposed heat fluxes averaged over the focus region are presented. In the experiment with a strong atmospheric forcing, three vigorous cold air outbreak events can be recognized, with oceanic heat loss exceeding $400 \mathrm{~W} / \mathrm{m}^{2}$ and reaching about $620 \mathrm{~W} / \mathrm{m}^{2}$ by day 7 . In the experiment with a weak atmospheric forcing, instead, a first phase 


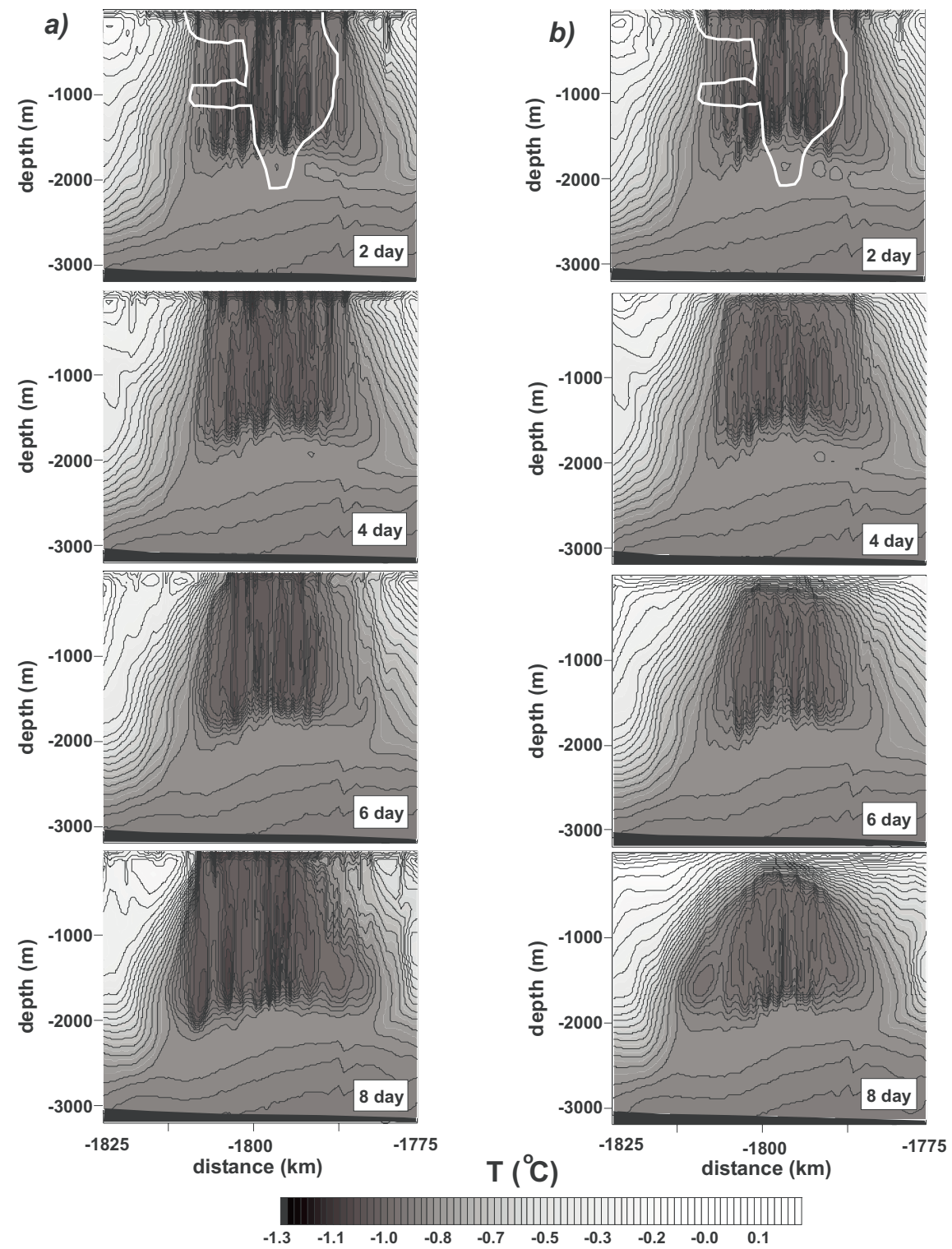

Figure 4: Vertical sections showing the simulated temperature through the chimney core for the different experiments at selected times: a) refers to the scenario with a strong atmospheric forcing, b) to the scenario with a weak atmospheric forcing. Note that the white line indicates the $-0.92^{\circ} \mathrm{C}$ isotherm, which is considered here as the isotherm separating the observed chimney from the ambient ocean.

characterized by an average heat loss of around 200 $\mathrm{W} / \mathrm{m}^{2}$ is followed by a phase of noticeable heat gain (circa $200 \mathrm{~W} / \mathrm{m}^{2}$ ). In Fig. 4 vertical sections showing the simulated temperature through the chimney core for the two experiments at selected times are presented. In both cases, the preconditioning induced by the presence of the mesoscale chimney to open-ocean deep convection is evident, as, initially, small-scale convective vertical plumes develop almost exclusively within its core region. As time elapses, vigorous heat loss in the experiment characterized by a strong atmospheric forcing triggers violent deep convection which brings newly formed dense water as deep as $2000 \mathrm{~m}$ and substantially contribute to preserve a large chimney surface outcropping area. This area, in the experiment characterized by a weak atmospheric forcing, is largely eroded at the end of the simulation time, for which the chimney has transformed in a surface/intermediate vortex. Note, however, that in both cases the chimney coherence is substantially preserved (Fig. 4).

The horizontal distribution of the sea surface temperature as simulated in the two experiments for selected times is presented in Fig. 5. In both experiments it can be noted that the imposed cooling and the resulting plume activity initially produce small-scale patches of surface temperature (typical surface length is less than $1 \mathrm{~km}$ ) which, as time elapses, tend to transform into elongated, larger-scale features, from which larger, mesoscale meanders evolve (typical surface length is more than $10 \mathrm{~km}$ at the end of the simulation time). These meanders tend 

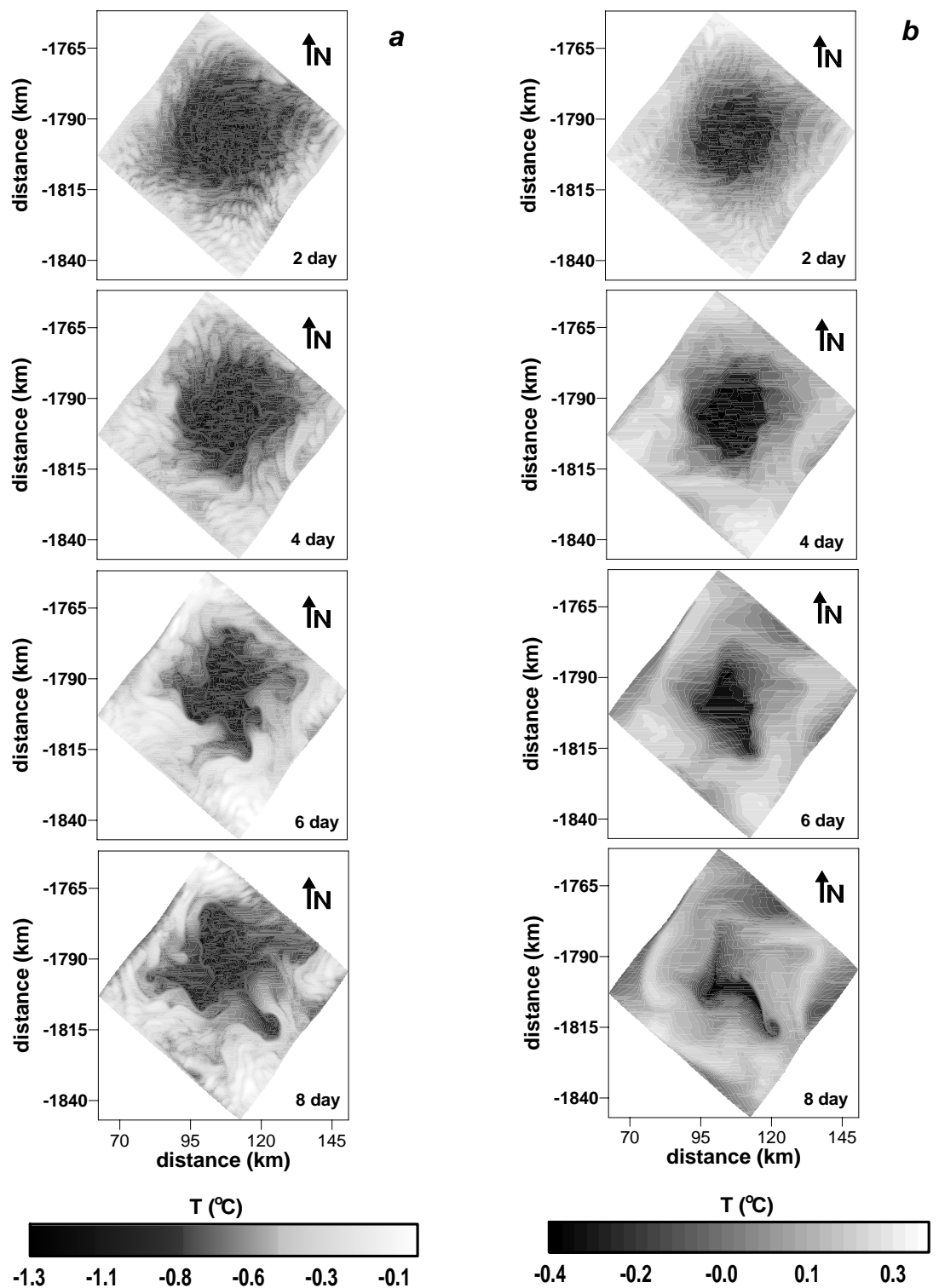

Figure 5: Simulated surface temperature for the different experiments at selected times: a) refers to the scenario with a strong atmospheric forcing, b) to the scenario with a weak atmospheric forcing.

to detach patches of newly formed water from the chimney core. This phase of lateral exchange and spreading is evident in both experiments, although much stronger in the experiment characterized by a strong atmospheric forcing.

\section{Long-term numerical experiments}

In order to investigate the long-term influence exerted by the presence of the observed convective chimney in the central Greenland Sea, we performed two simulations which differ merely for the fact that only in one of them the structure of the observed chimney was inserted as a part of the forcing in the central Greenland Sea, like in the two short-term experiments of the last section, whilst, in the other one, no chimney was inserted. In Fig. 6 the simulated Brunt-Väisälä period is plotted, for both experiments, as a function of time and depth in the centre of the quasi-permanent cyclonic gyre of the central Greenland Sea. Note that the insertion of the convective chimney (Fig. 6) corresponds to a period of strong convective preconditioning in the central Greenland Sea, visible in the large values of the BruntVäisälä period. After the insertion, the water mass stability in the central Greenland Sea from the near surface layers to $2000 \mathrm{~m}$ depth as simulated in the two experiments largely differ. In fact, while in the first case it increases substantially during summer time and decreases only slightly during the next winter, in the second case it increases only marginally during summer time and decreases strongly during the next winter. The initial presence of the chimney constituted thus in this case a strong element of preconditioning to next episodes of openocean deep-penetrating convection. 

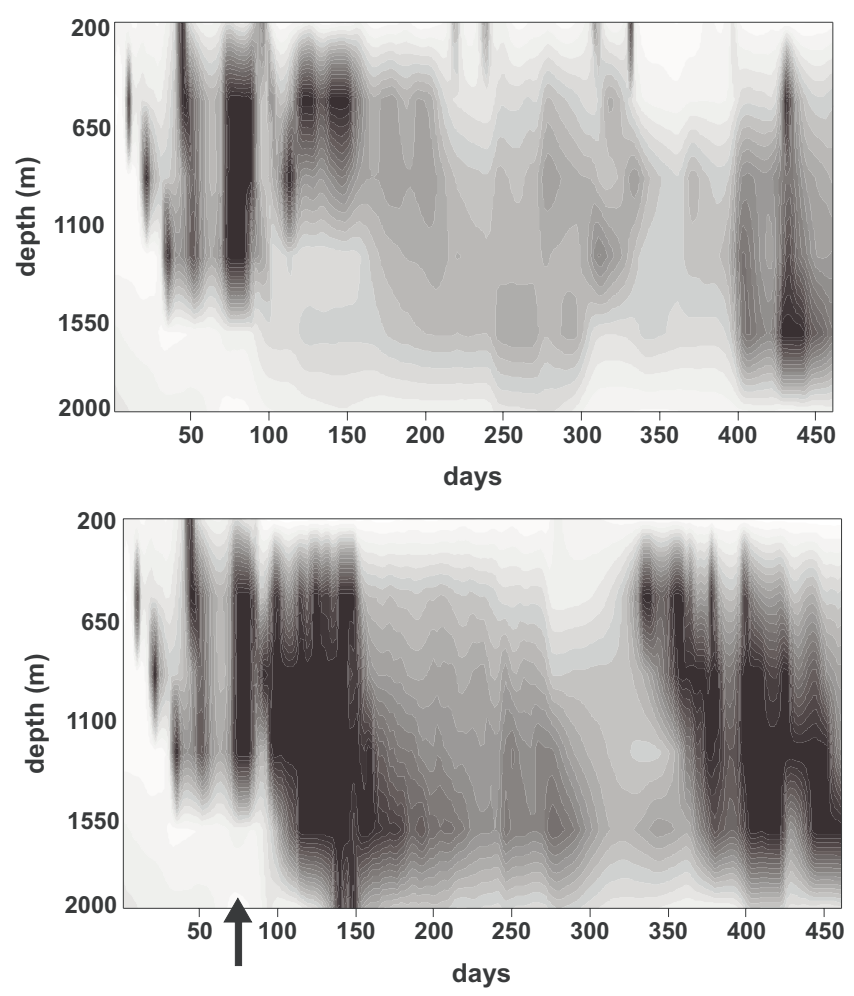

T, hours

$\begin{array}{lllllllllllll}0 & 1 & 2 & 3 & 4 & 5 & 6 & 7 & 8 & 9 & 10 & 11 & 12\end{array}$

Figure 6: Simulated Brunt-Väisälä period for the experiment without the insertion of the chimney (upper panel) and for the experiment with the insertion of the chimney (lower panel) as a function of time and depth in the centre of the quasi-permanent cyclonic gyre of the central Greenland Sea. Note that the arrow at the base of the lower panel marks the chimney insertion time.

\section{On the detectability of open-ocean deep convection in SAR imagery}

In a recent paper devoted at assessing the possibility of detection of oceanic convective phenomena using Synthetic Aperture Radar (SAR) imagery, ROMEISER et al. (2004) presented academic simulations performed using GNOM in which, in the case of a weak atmospheric forcing, only weak theoretical radar signatures of convective events were produced. In that study it was found that the sea surface manifestations of open-ocean, deeppenetrating convection are usually not sufficiently strong to become visible in SAR images from existing or former satellites such as Envisat, Radarsat-1, or ERS-1 / ERS-2. However, they should be more pronounced in images from upcoming high-resolution SAR systems such as Radarsat-2 and the German TerraSAR-X, which will permit a significant reduction of speckle noise fluctuations by averaging over many independent samples. Inserting the surface velocity field simulated in our experiment with a strong atmospheric forcing in the radar model of ROMEISER et al. (1997; see also ROMEISER and ALPERS, 1997) pronounced theoretical radar signatures were produced (Fig. 7), which could be detected not only in upcoming high-resolution SAR systems, but also in existing synthetic aperture radar data, if wind conditions were favourable (say, surface wind speed below $5 \mathrm{~m} / \mathrm{s}$ and absence of strong spatial variation in the surface wind field). The difference between our results and the results of ROMEISER et al. (2004) can be explained by the fact that we considered a strong atmospheric scenario, as the difference in the grid step and in the oceanic conditions in these two investigations are negligible. It seems thus that, in both studies, the numerical model was able to capture realistically the frontal structures inherent in the submesoscale plume activity. Indeed, the actual convergent regions in the surface current field of frontal phenomena that give rise to SAR signatures via hydrodynamic wave-current interaction are usually narrower and stronger than represented in typical numerical models with grid resolutions coarser than $\mathrm{o}(100 \mathrm{~m})$. To generate fully adequate surface current fields for SAR simulations, one would need to completely resolve the spatial structures of oceanic fronts, which is not feasible with currently available hydrodynamic models and computing power. To get an impression of the effect of model resolution on the simulated surface signatures of convection, we have simulated the same convective event using four different grid resolutions in an idealized context characterized by a closed domain cooled in its central region to produce convection. Using such a model configuration we were able to simulate a 8-day period with grid step reaching $55 \mathrm{~m}$. Results are shown in Fig. 7, where the simulated maximum horizontal velocity convergences as a function of time are depicted.

In general, the simulated maxima increase as the model resolution increases. In particular, we note that, doubling the (rectangular) grid resolution from $250 \mathrm{~m}$ to $125 \mathrm{~m}$ yields approximately a doubling in the simulated mean maxima, while doubling the (curvilinear) resolution from $125 \mathrm{~m}$ to $55 \mathrm{~m}$ yields an increase of about $50 \%$ in the simulated mean maxima (Fig. 8). This is due on the one hand to the fact that the curvilinear resolution is variable, its maximum being located in points which not necessarily coincide with convective spots, and, on the other hand, to the fact that, as stressed before, a resolution around $100 \mathrm{~m}$ starts to capture adequately the frontal structure associated to small-scale convective plumes. Still, an increase in the resolution from $125 \mathrm{~m}$ to $55 \mathrm{~m}$ (Fig. 8) brings a substantial improvement in the strength of the simulated convergence field.

\section{Conclusions}

In the present study, for the first time, a hierarchy of nested numerical models was implemented to study, under realistic conditions, the role played by mesoscale, 
ERS-2 SAR

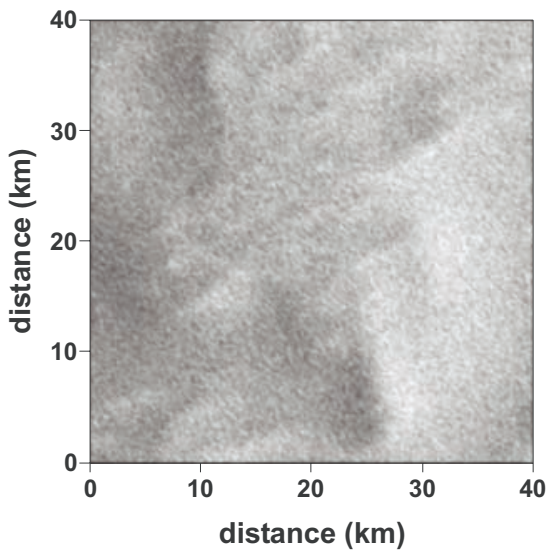

TerraSAR-X (VV)

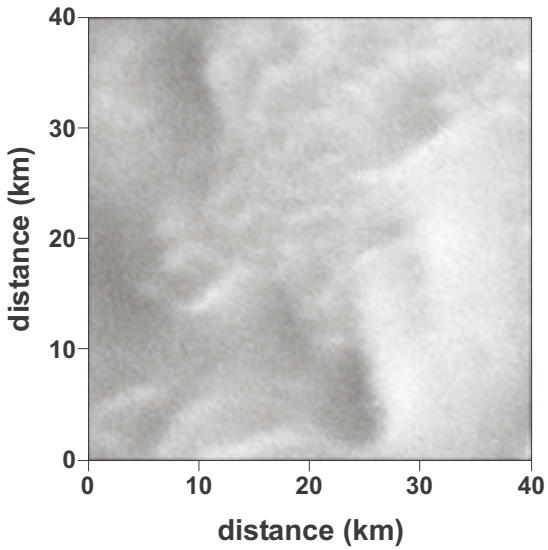

RADARSAT-1 SAR

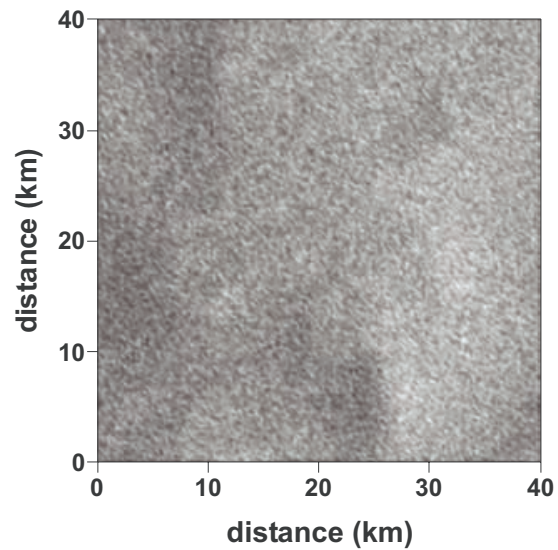

TerraSAR-X (HH)

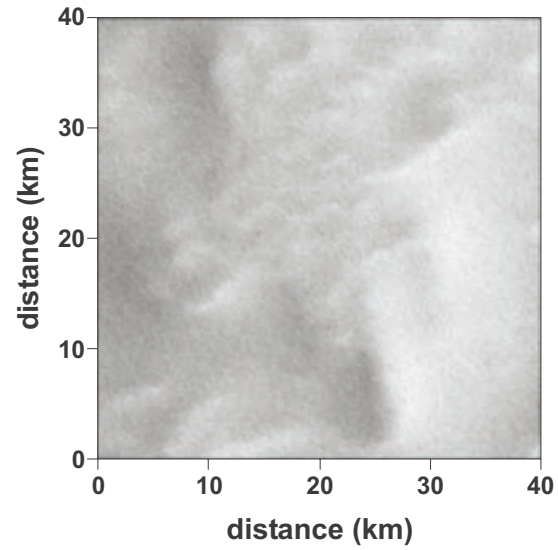

Figure 7: Examples of simulated ERS-2 (left upper panel), RADARSAT-1 (right upper panel), TerraSAR-X (VV) (left lower panel), and TerraSAR-X (HH) (right lower panel) signatures of the surface current field simulated by GNOM, in the scenario with a strong atmospheric forcing, within the convective region of the Central Greenland Sea at day 6. The realizations refer to a realistic speckle noise statistics.

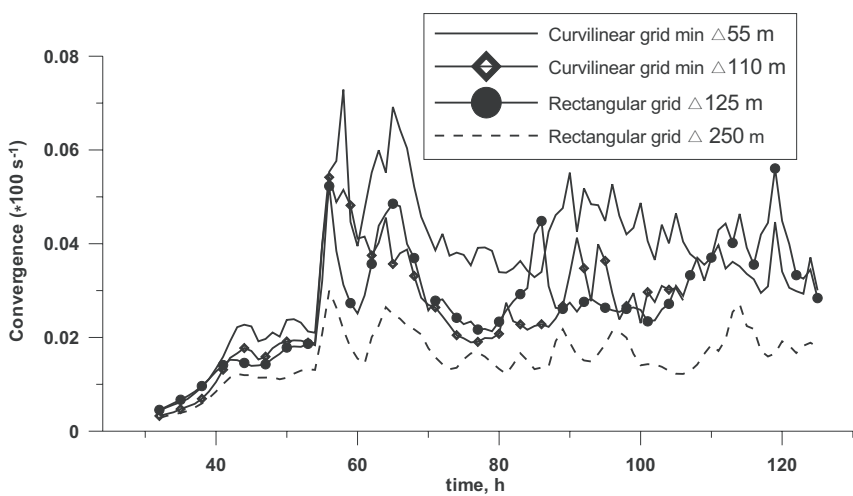

Figure 8: Maximum value of simulated surface horizontal convergence field as a function of time for the same convective event simulated with different model grid resolutions.

convectively generated chimneys in the preconditioning to open ocean convection in the Greenland Sea. A very high resolution, fully non-hydrostatic $3 \mathrm{D}$ model, in which the structure of a realistic mesoscale chimney similar to that observed by WADHAMS et al. (2002) in the central Greenland Sea was imposed, was nested into an ocean-ice, hydrostatic regional model which was initialised and forced through the global, coupled atmosphere ocean 3D REMO/MPI-OM model. The results of two short term numerical experiments elucidate the development of convectively generated submesoscale as well as mesoscale oceanic vortical features under realistic conditions. In particular, it is found that mesoscale vortices develop from small-scale elongated features at the rim of the inserted chimney having typical horizontal lengths smaller than $1 \mathrm{~km}$ : their adequate resolution (together with the resolution of the even smaller features forming the meanders from which these features emerge) seems to be thus important to capture the horizontal export of newly formed water in numerical models. The results of the short term experiments also indicate that the inserted chimney tended to preserve its coherence as a surface vortex in the case of strong atmo- 

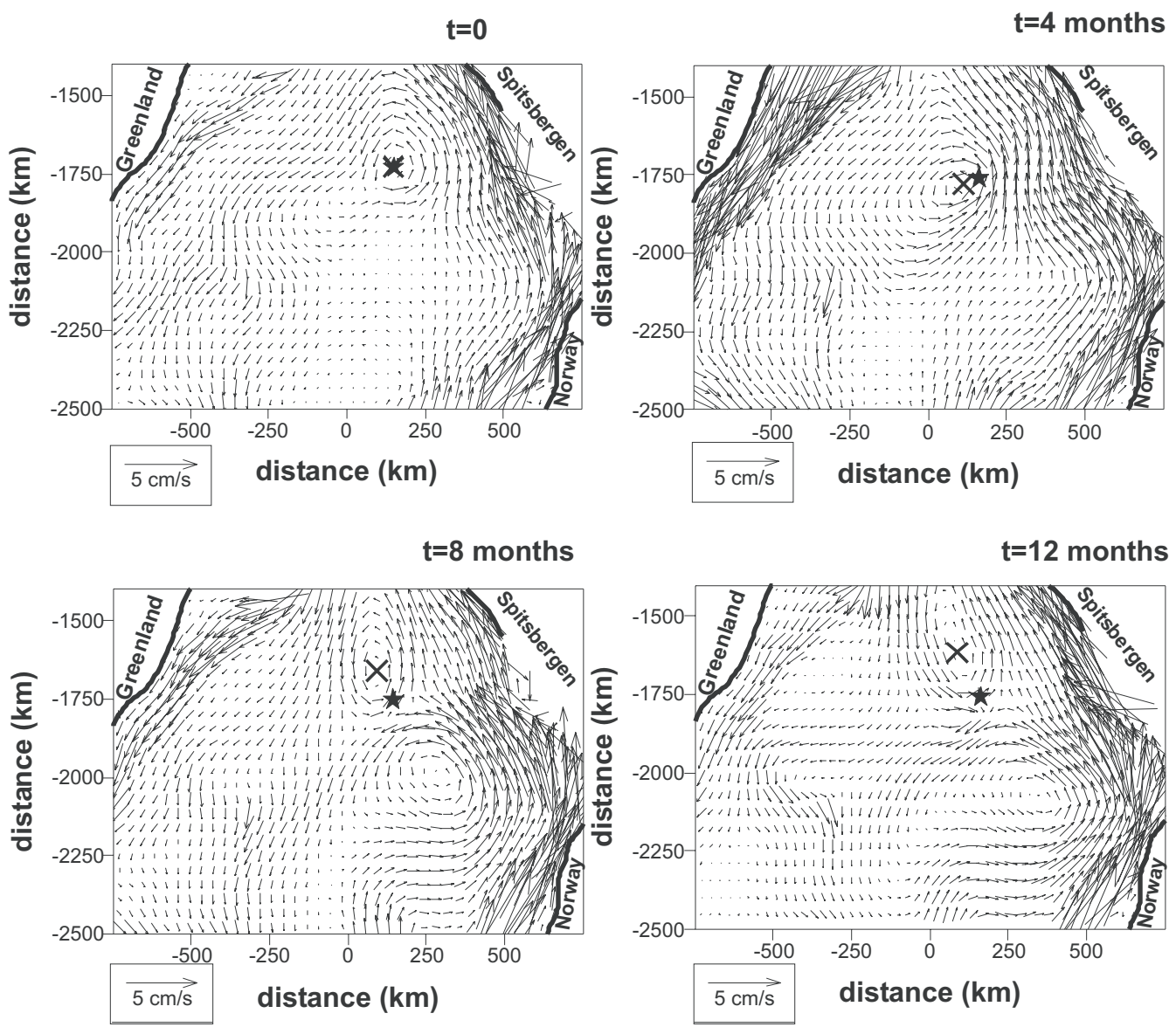

Figure 9: Positions of the centre of the quasi-permanent cyclonic gyre of the central Greenland Sea (cross) and of the chimney (stars) for selected times after the insertion of the chimney.

spheric forcing and as an intermediate vortex in the case of a weak atmospheric forcing. This tendency to preserve its coherence characterized also a long-term run. In the central Greenland Sea the inserted chimney left trace of its presence throughout the simulation period successive to its insertion (15 months). It contributed to destabilize the upper $2000 \mathrm{~m}$ of the water column there, which constitutes a significant element of preconditioning to deep penetrating, open ocean convection. Probably, this longevity of convectively generated vortical features in the central Greenland Sea is connected with the presence of a quasi-permanent cyclonic gyre there, which may be able, at least partly, to trap coherent water masses located near its centre. This conjecture seems to be justified by the results of our long term simulation: in Fig. 9 the positions of the centre of the quasi-permanent cyclonic gyre of the central Greenland Sea and those of the inserted chimney as simulated by our numerical model are depicted for selected times. The distance between these two centres, which was zero at the insertion time, never exceeded $140 \mathrm{~km}$. As a comparison, tracers we injected, at the sea surface as well as in the interior layers, in different positions of the Greenland Sea, were strongly advected by the local currents.
Finally, a sensitivity study was carried out to elucidate the dependence of simulated surface convergence patterns, which, substantially, constitute the link between sea surface signatures of oceanic and atmospheric phenomena and radar images of the sea surface, on grid step. It is found that only very high horizontal resolutions $(\mathrm{o}(100 \mathrm{~m}))$ seem to produce realistic surface signatures of frontal features like those characteristic of episodes of open ocean deep penetrating convection. The capability of numerical models of predicting the detectability of convective events in SAR imagery depend thus crucially on the numerical resolution achieved in the oceanic model.

\section{Acknowledgements}

The authors would like to thank Jürgen HOLFORT for having provided the measured data of the convective chimney used in the numerical simulations and Detlef STAMMER for his helpful comments.

\section{References}

Androsov A.A., N.E. Voltzinger, 2005: World Ocean Straits. A General Approach to Modelling. - Nauka. P. 188. 
Androsov A.A., K.A. Klevanny, E.S SAlusti, N.E VOLTZINGER, 1995: Open boundary conditions for horizontal 2-D curvilinear-grid long-wave dynamics of a strait. - Advances in Water Resources 18, 267-276.

ANDROSOV A.A., N.E. VOLTZINGER, D.A. ROMANENKOV, 2002: Simulation of Three-Dimensional Baroclinic Tidal Dynamics in the Strait of Messina. - Izv. AN, FAO 38, No 1, 119-134.

Gascard, J.-C., A.J. Watson, M.-J. Messias, K. A. Olsen, T. Johannesen, K. SimOnSEN, 2002: Longlived vortices as a mode of deep ventilation in the Greenland Sea. - Nature 416, 525-527.

HIBLER W.D., 1979: A dynamic thermodynamic sea ice model. - J. Phys. Oceanogr. 9, 815-846.

JACOB, D., R. PODZUN, 1997: Sensitivity studies with the regional climate model REMO. - Meteor. Atmos. Physics 63, 119-129.

LEGG, S., J. MARShall, 1998: The influence of the ambient flow on the spreading of convected water masses. - J. Mar. Res. 56, 107-139.

MAHADEVAN A., J. Oliger, R. Street, 1996: A nonhydrostatic mesoscale ocean model part 1,2 . - J. Phys. Oceanogr. 26, 1868-1900.

MAIER-REIMER, E., 1997: Design of the closed boundary regional model of the Arctic ocean. - Bull. Amer. Meteor. Soc.: Workshop on polar processes in global climate 13-15 Nov. 1996, 72-73.

MARShall, J., F. SChOTT, 1999: Open-ocean convection: observations, theory, and models. - Rev. Geophys. 37, 164.

MEDOC GROUP, 1970: Observations of formation of deepwater in the Mediterranean Sea, 1969. - Nature 227, 10371040.
RoAch, A.T., K. AAGaARD, F.D. CARSEy, 1993: Coupled ice-ocean variability in the Greenland Sea. - Atmos. Ocean 31, 319-337.

ROMEISER, R., W. AlPERS, 1997: An improved composite surface model for the radar backscattering cross section of the ocean surface, 2, Model response to surface roughness variations and the radar imaging of underwater bottom topography. - J. Geophys. Res. 102, 25,251-25,267.

ROMEISER, R., W. Alpers, V. WiSMANN, 1997: An improved composite surface model for the radar backscattering cross section of the ocean surface, 1 , Theory of the model and optimization/validation by scatterometer data. J. Geophys. Res. 102, 25,237-25,250.

Romeiser R., S. Ufermann, A. Androssov, H. WeHDE, L. Mitnik, S. Kern, A. Rubino, 2004: On the remote sensing of oceanic and atmospheric convection in the Greenland Sea by synthetic aperture radar. - J. Geophys. Res. 109, C03004, doi:10.1029/2003JC001975.

SCHOTT, F., M. VisBeCK, J. FisCHER, 1993: Observations of Vertical Currents and Convection in the Central Greenland Sea During the Winter of 1988-1989. - J. Geophys. Res. 98, C8, 14,401-14,421.

Valcke, S., L Terray, A Piacentini, 2000: OASIS: Ocean Atmosphere Sea Ice Soil version 2.4, User's guide. - CERFACS internal report No TR/CGMC/00-10.

Visbeck, M., J. Fischer, F. SCHOTT, 1995: Preconditioning the Greenland Sea for deep convection: Ice formation and ice drift. - J. Geophys. Res. 100, 18,489-18,502.

WADHAMS, P., J. Holfort, E. HANSEN, J.P.Wilkinson, 2002: A deep convective chimney in the winter greenland sea. - Geophys. Res. Lett. 29, 1-9. 